\title{
Supplementary Materials:
}

(The Indian Summer Monsoon Rainfall: Interplay of Coupled Dynamics, Radiation and Cloud Microphysics, By Prabir K. Patra et al.)
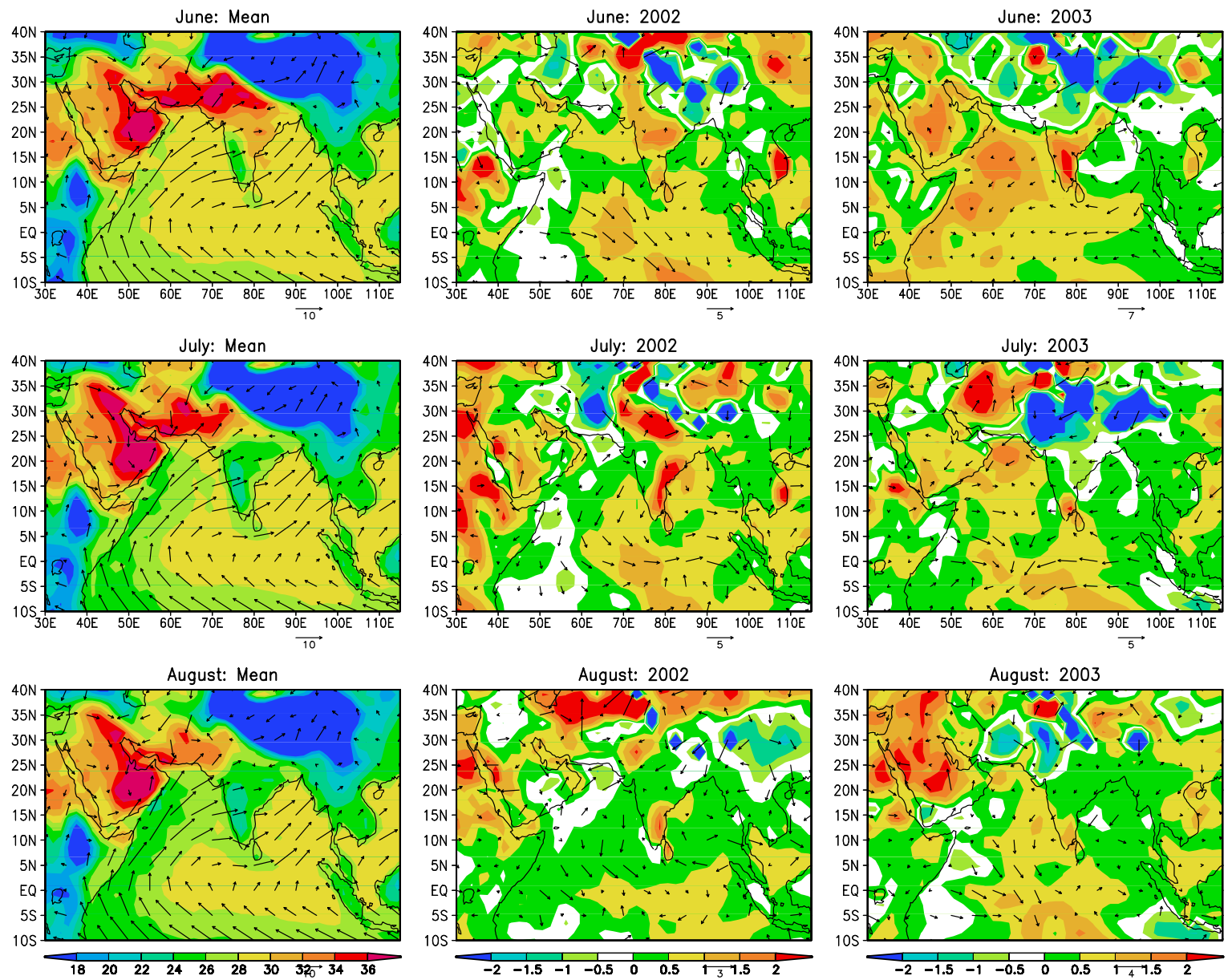

Figure S1. Surface temperature $\left({ }^{\circ} \mathrm{C}\right)$ and surface wind vector: Mean (1979-02) and anomalies for 2002 and 2003.

Definition of Aerosol Index (from http://toms.gsfc.nasa.gov):

The TOMS aerosol index is a measure of how much the wavelength dependence of backscattered UV radiation from an atmosphere containing aerosols (Mie scattering, Rayleigh scattering, and absorption) differs from that of a pure molecular atmosphere (pure Rayleigh scattering). Quantitatively, the aerosol index AI is defined to be 


$$
A I=-100 \cdot \log _{10}\left[I_{331}^{\text {Meas }} / I_{360}^{\text {Calc }}\right]
$$

where $I_{331}^{\text {Meas }}=$ the measured $331 \mathrm{~nm}$ EP-TOMS radiance

$$
I_{360}^{\text {Calc }}=\text { the calculated } 360 \mathrm{~nm} \text { EP-TOMS radiance for a Rayleigh atmosphere }
$$

Under most conditions, the AI is positive for absorbing aerosols and negative for nonabsorbing aerosols (pure scattering).
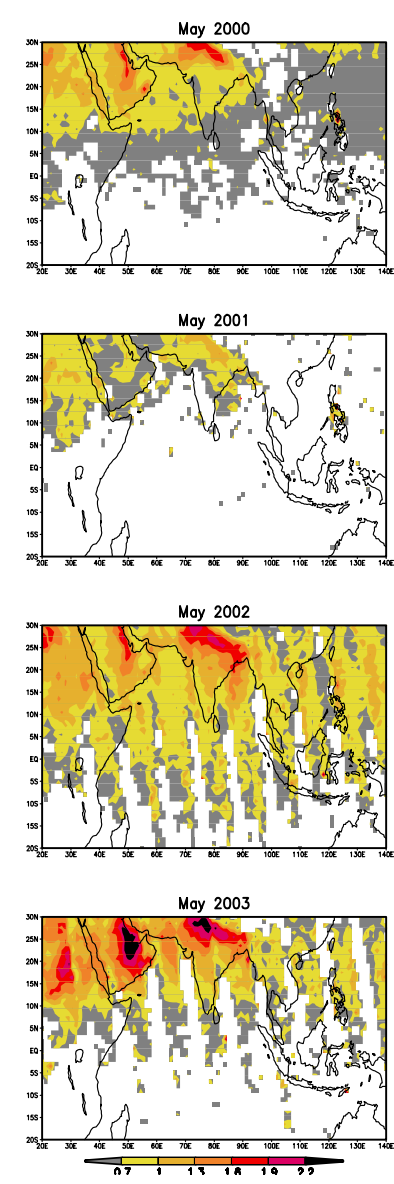
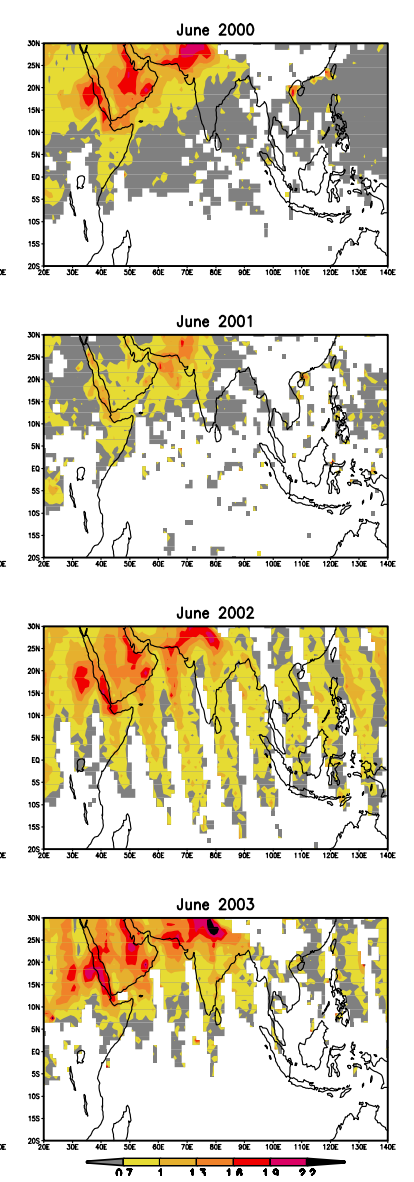
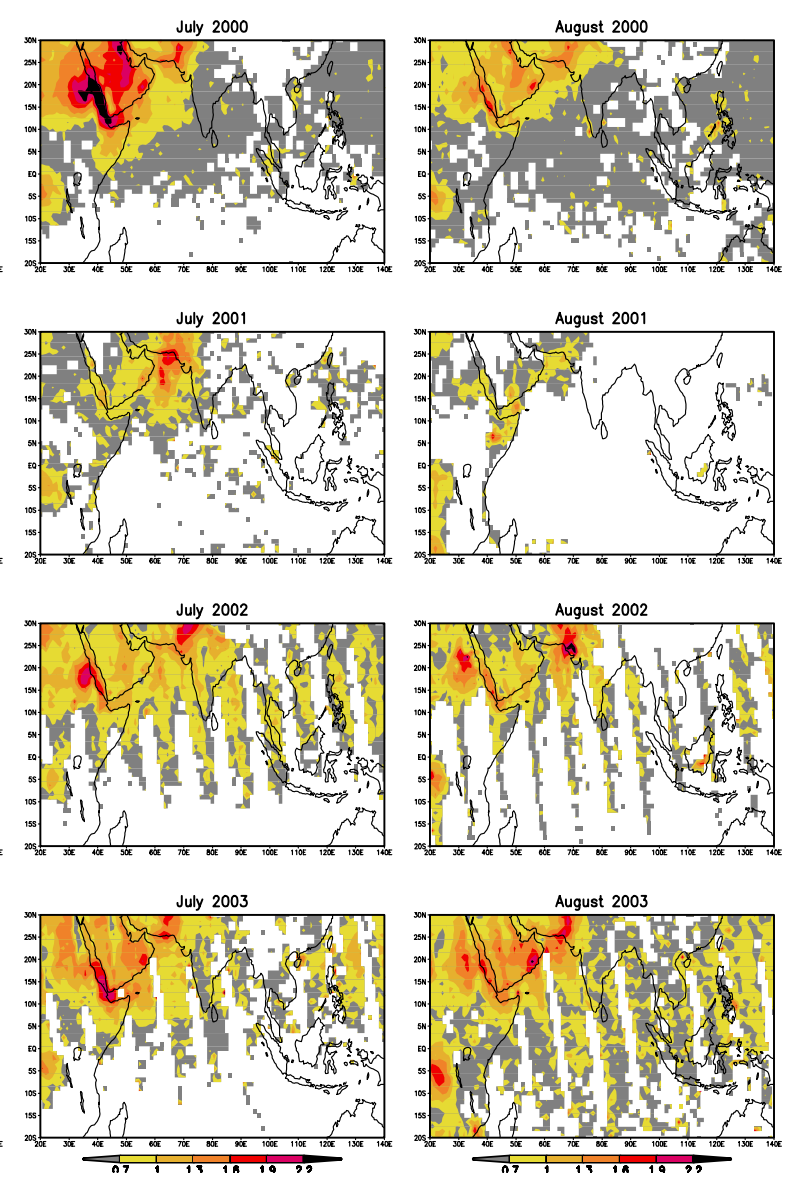
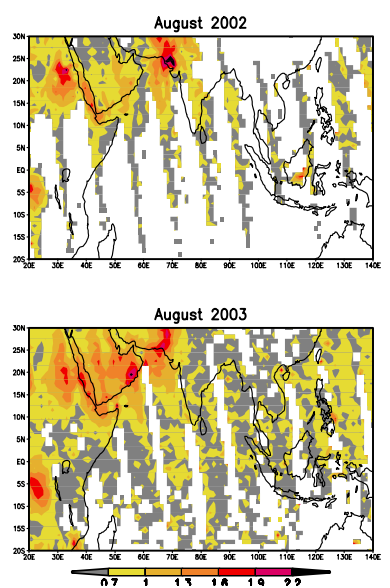

Figure S2. Spatial distributions of monthly mean Aerosol Index for the period 2000-2003 during the May-August months. AI is an indicator of the thickness of the absorbing (AI>0.4) aerosol column. The TOMS AI is selected over MODIS AOD for this plot because MODIS data have gaps over large areas in northern Africa and the Middle-East. 
The GIF formatted animations for daily Aerosol Index as observed from TOMS satellite are also produced for May-June-July-August period of 2001 (M1), 2002 (M2) and 2003 (M3). These animations clearly demonstrate the transport of aerosols from Africa-Arabia continents to the north-west India region. We have kept the animation files at our website and can be viewed using Netscape or Windows Media Player following this link: http://www.jamstec.go.jp/frsgc/research/d4/prabir/anim_ai.htm

Alternative to the daily AI animations and monthly mean AIs, we also have done the COtracer, a proxy for biomass burning activity, simulations to monitor the level of biomass burning by products over the Indian monsoon domain. The CO-like tracers are constructed from the monthly ATSR World Fire Atlas for fire counts at 1x1 degree horizontal resolution (from http://dup.esrin.esa.int/ionia/wfa/). The tracer simulations are conducted using the FRCGC/NIES global chemistry-transport model (CTM), where the tracer loss rates are formulated using $\mathrm{CO}+\mathrm{OH}$ chemical reaction (Maksyutov and Inoue, 2000). Typical $\mathrm{OH}$ distributions are taken from Spivakovsky et al. (2000). The model transport is driven by NCEP/NCAR reanalysed meteorology fields (6 hourly; $2.5 \times 2.5$ degrees horizontal resolution interpolated to 15 layers of the CTM) for the respective years. Figure S3 shows that the biomass burning activity over the Indian region is almost non-existing during June-July while a significant level of fire counts are observed over the Middle-East from the ATSR maps. Though the interannual variability in total fire counts does not appear to be very large, how much of the resultant pollutants can reach the Indian monsoon domain is linked to the prevalent dynamics (controlled by the oscillations) and distribution of the fire maps. More fire events are recorded in the southern part of the Middle-East (around Oman and Saudi Arabia) in 2002 compared to other years. The biomass burning products from the Tropical and Southern Africa regions are transported westward during this season. The MOPITT CO distributions at $850 \mathrm{hPa}$ also indicate higher $\mathrm{CO}$ concentrations in the north-western India, Middle-East and the region in between in July 2002 compared to July 2003 (www.eos.ucar.edu/mopitt/). It should be mentioned here that our CTM does not account for interannual variations in $\mathrm{OH}$ due to the changes in atmospheric composition. However, some studies have shown that the drier atmospheric condition (like 2002) would increase the residence time of pollution (both aerosols and gases) in the atmosphere (e.g. Sudo and Takahashi, 2001). Note here that some false fire alarms may have been counted in ATSR Fire 
Atlas from the 'dead zone' (no vegetation) parts of the Arabian Peninsula, but the discussion on typical transport patterns remain valid.
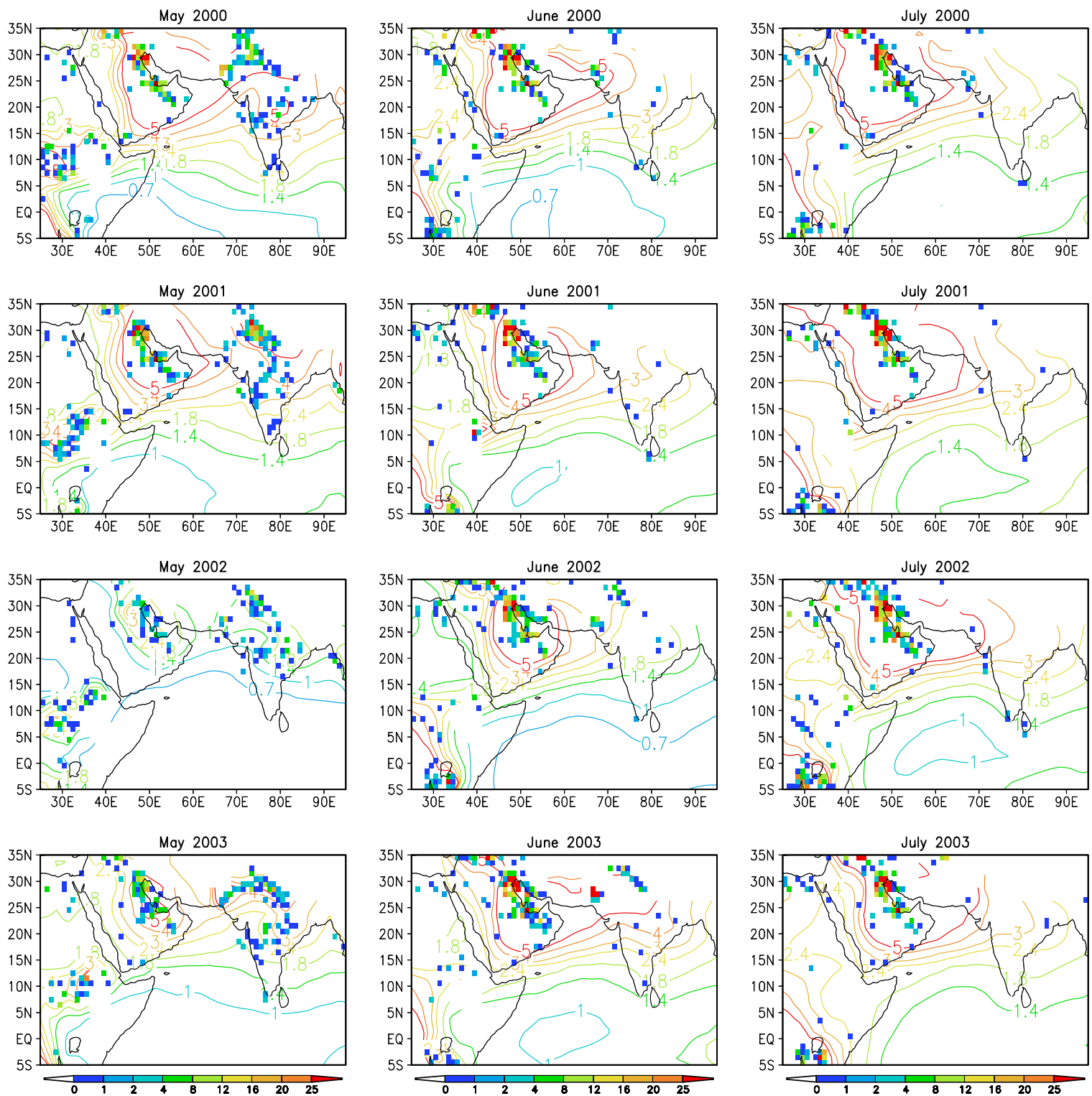

Figure S3: Monthly mean distributions of CO-like tracers (contour) of ATSR fire counts (shaded) for the period 2000-2003 during May-June-July. Note that the tracer isopleths at 850 hPa with value 3 covered the most parts of the north Indian subcontinent in July 2002, and the isopleths with value 4 covers the north-western part of India where the cloud effective radius values were very small (see Fig. S4). 

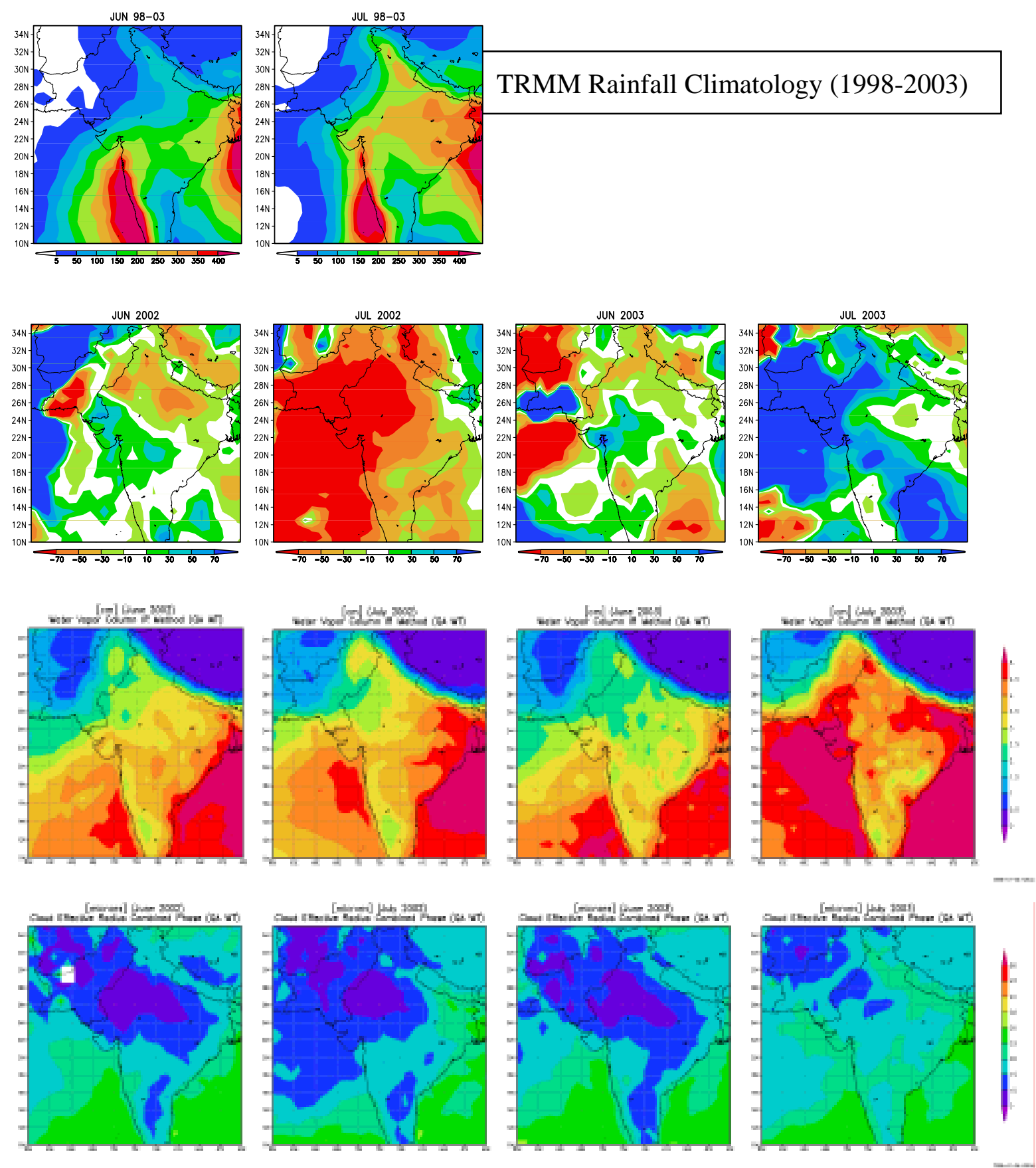

Figure S4. Monthly mean distribution of TRMM rainfall climatology (in mm/month, top row), TRMM rainfall departure from climatology (in $\%, 2^{\text {nd }}$ row from top), MODIS water vapour column (in $\mathrm{cm}, 3^{\text {rd }}$ row from top) and combined phase cloud effective radius (in microns, bottom row) for June 2002 ( $1^{\text {st }}$ column from left), July 2002 ( $2^{\text {nd }}$ column from left), June 2003 ( $3^{\text {rd }}$ column from left) and July 2003 (right column). Note here that no clear correlation between water vapour column and cloud effective radius can be found, but a broad connection between CER and rainfall anomaly are seen. 
14-16 July 2001

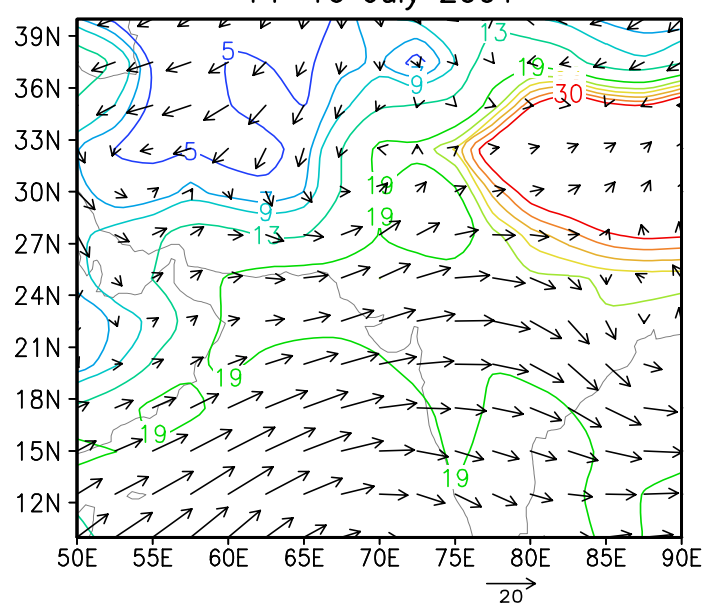

2-4 July 2003

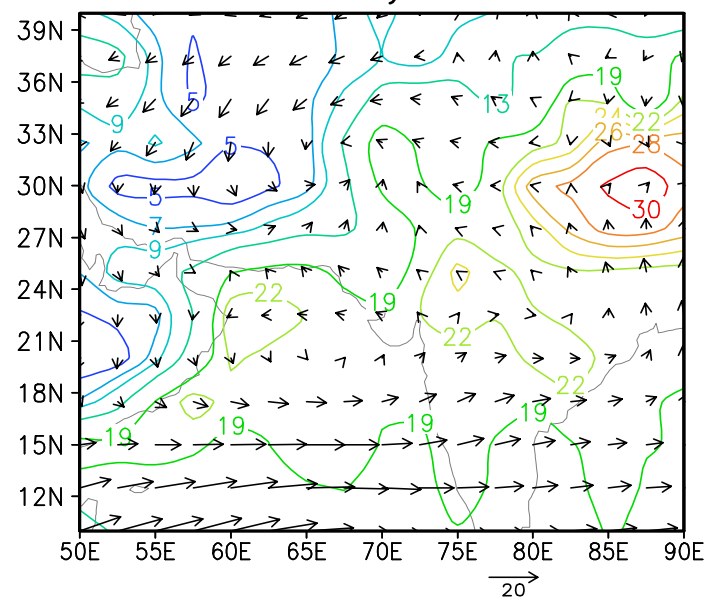

$23-25$ July 2002

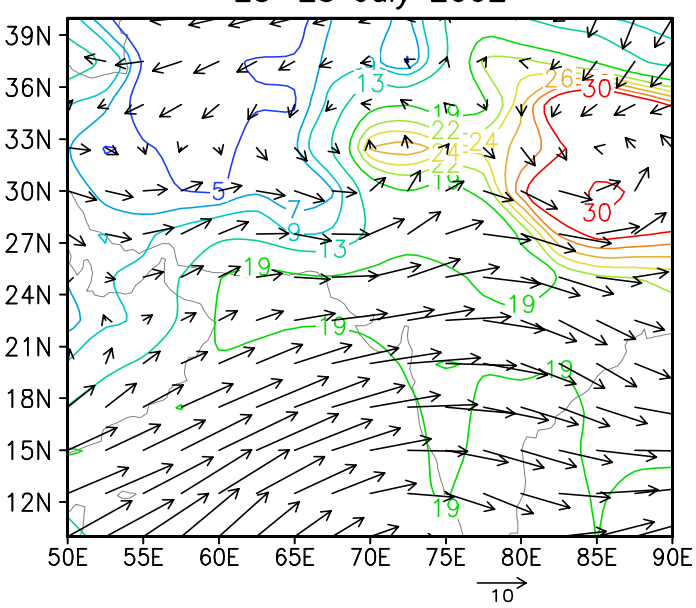

$13-15$ July 2003

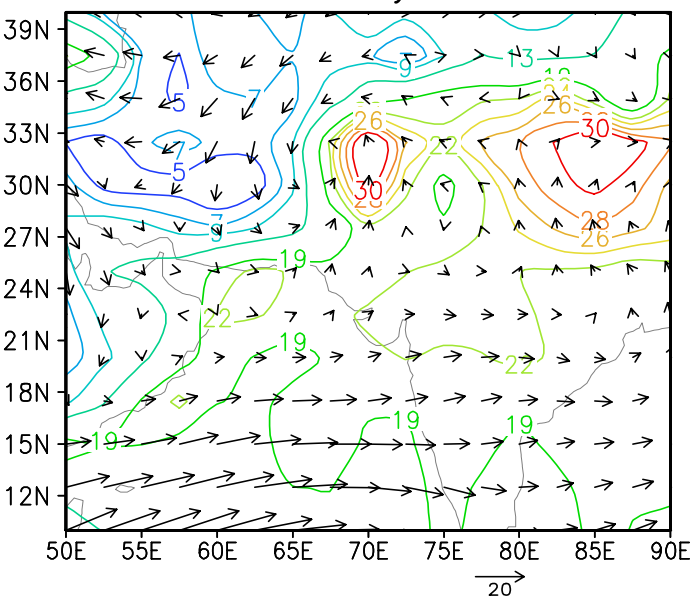

Figure S5. Distribution of wind vectors (in $\mathrm{m} / \mathrm{s}$ ) at $850 \mathrm{hPa}$ layer, and specific humidity at $1000 \mathrm{hPa}$ (in $\mathrm{g} / \mathrm{kg}$ ) from NCEP/NCAR reanalysis datasets for selected 3 day periods. The selection of two time periods (top panels) are based on Fig. 4, when higher wind speed, larger aerosol amount and low rainfall were observed (14-16 July 2001 and 23-25 July 2002). Two other periods (bottom panels) are also selected in July 2003 when lower wind speed, lesser aerosol amount and heavy rainfall were observed (2-4 July 2003 and 13-15 July 2003). Note here that significant differences are observed only in the horizontal transport patterns, and the differences in specific humidity were not very prominent during the spells of heavy (lower panels) and light (upper panels) rainfall. 


\section{References:}

Maksyutov, S., and G. Inoue, Vertical profiles of radon and $\mathrm{CO} 2$ simulated by the global atmospheric transport model, CGER/NIES-I039-2000 (7), 39-41, 2000.

Spivakovsky, C. M., et al., Three-dimensional climatological distribution of tropospheric $\mathrm{OH}$ : Update and evaluation, J. Geophys. Res. 105, 8931-8980, 2000.

Sudo, K., and M. Takahashi, Simulation of tropospheric ozone changes during 1997-1998 El Niño: Meteorological impact on tropospheric photochemistry, Geophys. Res. Lett. 28, 40914094, 2001. 